\title{
PENGARUH KECERDASAN EMOSIONAL DAN SIKAP SISWA TERHADAP PEMAHAMAN KONSEP KIMIA
}

\author{
Theresia Evy Yulianty Nadeak \\ Program Studi Teknik Industri, Universitas Indraprasta PGRI \\ Email: theresianadeak2082@gmail.com
}

\begin{abstract}
Abstrak
Sikap yang positif terhadap suatu mata pelajaran akan membawa keseriusan dalam mempelajarinya. Sebaliknya, sikap yang negatif akan membawa siswa semakin menjauhi mata pelajaran, yang pada akhirnya mempengaruhi tinggi rendahnya kemampuan siswa dalam memahami konsep terutama dalam mata pelajaran kimia. Tujuan dari penelitian ini untuk mengetahui apakah ada pengaruh kecerdasan emosional dan sikap siswa terhadap pemahaman konsep kimia siswa terutama pada SMA Negeri di Jakarta Selatan. Jenis penelitian kuantitatif dengan metode survei dan teknik analisis regresi ganda. Teknik pengambilan data dengan cara penyebaran angket untuk data kecerdasan emosional dan sikap siswa serta tes butir pilihan ganda untuk pemahaman konsep kimia. Populasi penelitian yaitu siswa kelas X SMA Negeri di Jakarta Selatan tahun pelajaran 2018/2019 yang berjumlah 858 siswa dengan sampel 90 siswa. Hasil penelitian menyimpulkan bahwa : 1) Terdapat pengaruh yang signifikan kecerdasan emosional dan sikap siswa secara bersama-sama terhadap pemahaman konsep kimia siswa SMA Negeri di Jakarta Selatan dengan kontribusi sebesar 52,2\%. 2) Terdapat pengaruh yang signifikan kecerdasan emosional terhadap pemahaman konsep kimia siswa SMA Negeri di Jakarta Selatan dengan kontribusi sebesar 24,60\%. 3) Terdapat pengaruh yang signifikan sikap siswa terhadap pemahaman konsep kimia siswa SMA Negeri di Jakarta Selatan dengan kontribusi sebesar $9,69 \%$.
\end{abstract}

Kata Kunci : Pemahaman Konsep Kimia, Kecerdasan emosional, Sikap siswa

\begin{abstract}
A positive attitude towards a subject will lead students to full attention to studying it. On the other hand, a negative attitude will take the students away from the subject which in turn affects the level of student's ability to understand concepts, especially in chemistry. The purpose of this study is to determine whether there are effects of emotional intelligence and students' attitude towards students' understanding of chemical concepts, especially in public Senior High School in South Jakarta. This research occupied a quantitative method using survey and multiple regression analysis techniques. Data collection was conducted by distributing questionnaires for emotional intelligence and student attitude, and multiple-choice items test for understanding chemical concepts. The population of this study was Grade X of Public Senior High School in South Jakarta, Academic Year 2018/2019, amounting to 858 students with a sample of 90 students. The results of this study concluded that 1) There is a significant influence of emotional intelligence together with attitudes of students on understanding the chemical concept of public senior high school students in South Jakarta with a contribution of 52.2\%. 2) There was a significant effect of emotional intelligence on the understanding of chemical concepts with a contribution of $24.6 \%$, 3) There was a significant effect of students attitudes on the understanding of chemical concepts with a contribution of $9.69 \%$.
\end{abstract}

Key Words : Understanding of Chemistry Concepts, Emotional Intelligence, Student Attitude

\section{PENDAHULUAN}

Kimia merupakan salah satu pelajaran wajib pada jenjang pendidikan di Sekolah Menengah. Pelajaran kimia bertujuan untuk membuat siswa agar mampu berpikir logis, kritis serta analitis. Dengan memperhatikan hal tersebut, maka pelajaran kimia seharusnya dapat dikuasai oleh siswa. Akan tetapi kenyataannya, pemahaman konsep siswa pada mata pelajaran kimia masih rendah dikarenakan mata pelajaran kimia dianggap sebagian besar siswa sebagai mata pelajaran yang 
sangat sepele oleh siswa, bahkan di sebagian siswa menganggap mata pelajaran kimia adalah mata pelajaran yang membosankan. Sikap dari siswa terhadap pelajaran kimia dapat kita ketahui dari cara siswa memberikan respon ketika kegiatan pembelajaran berlangsung. Peserta didik yang memiliki sikap positif, ia akan menganggap kimia itu sebagai pelajaran yang mudah dan asyik untuk dipelajari. Ia akan semangat dan selalu memperhatikan penjelasan dari guru ketika pembelajaran berlangsung [1]. Awal dari sikap inilah yang dapat mempengaruhi kecerdasan emosional serta kemampuan siswa dalam memahami konsep pada pelajaaran kimia.

Emosi merupakan suatu kekuatan penggerak dimana nilai-nilai dan watak dasar seseorang dalam hidup ini tidak berakar pada IQ tetapi pada kemampuan emosional [2]. Emosi berkaitan dengan perubahan fisiologis dan berbagai pikiran. Jadi, emosi merupakan salah satu aspek penting dalam kehidupan manusia, karena emosi dapat merupakan motivator perilaku/sikap dalam arti meningkatkan, tapi juga dapat mengganggu perilaku intensional manusia [3].

Emosional sebagai suatu yang berkaitan dengan ekspresi emosi, atau dengan perubahan-perubahan yang mendalam yang menyertai emosi. Sedangkan kecerdasan diartikan sebagai kemampuan seseorang dalam menggunakan konsep abstrak serta menghadapi dan menyesuaiakan diri terhadap situasi baru secara cepat dan efektif. Kecerdasan Emosional atau EQ adalah mengukur kemampuan seseorang dari aspek pengendalian dan pengembangan emosi [4]. Kecerdasan emosional merupakan kemampuan meliputi kemampuan untuk mengendalikan diri, memiliki daya tahan menghadapi sesuatu dan mampu mengatur suasana hatinya [5].
Pada dasarnya kecerdasan emosional tidak dapat dimiliki secara tiba-tiba tetapi membutuhkan proses dalam mempelajarinya dan lingkungan yang membentuk kecerdasan emosional tersebut besar pengaruhnya [6]. Siswa yang mampu mengenali emosi, mengelola emosi dan memotivasi diri memiliki kesadaran diri dan rasa bertanggungjawab untuk belajar sekalipun pada pelajaran yang dianggap sulit. Mengenali emosi orang lain dan membina hubungan sosial juga penting karena dalam lingkungan yang lebih luas, anak akan bersosialisasi dengan orang lain dan dari hubungan sosial yang terjadi, siswa akan mengalami proses belajar [7].

Berdasarkan definisi di atas, maka dapat disimpulkan bahwa kecerdasan emosional adalah kemampuan dalam menggunakan perasaan secara optimal untuk mengenal dan mengatur diri sendiri serta mengelola emosi yang terdapat dalam diri sendiri dan orang lain agar energi emosi tersebut pada waktu yang tepat dengan frekuensi yang cukup dapat diterapkan secara efektif dalam membina hubungan yang baik dengan orang lain. Oleh karena itu, emosi dan tingkahlaku/sikap mempunyai keterkaitan yang sangat erat. Seseorang yang tidak mampu mengontrol emosinya ia akan mengalami kesulitan untuk mengatasi masalah-masalah yang dihadapinya, baik masalah yang berhubungan dengan pembelajaran, pekerjaan maupun hal-hal lainnya [8].

Tujuan dari penelitian adalah untuk mengetahui secara empiris apakah ada pengaruh kecerdasan emosional dan sikap siswa secara bersama-sama terhadap pemahaman konsep kimia siswa pada SMA Negeri di Jakarta Selatan. Manfaat dari penelitian ini diharapkan dapat membuat siswa sebagai obyek penelitian menjadi lebih aktif dan memiliki sikap positif terhadap mata pelajaran yang diikutinya dalam hal ini mata pelajaran 
kimia agar dapat meningkatkan pemahaman konsep kimia, sedangkan bagi guru penelitian ini diharapkan berguna dalam usahanya meningkatkan pemahaman konsep dan sikap positif siswa terhadap mata pelajaran yang diasuhnya, dalam hal ini mata pelajaran kimia.

\section{METODE}

Penelitian ini dilaksanakan di SMA Negeri pada wilayah Jakarta Selatan. Penelitian ini pelaksanaannya selama 4 bulan mulai dari bulan Maret sampai dengan bulan Juni Tahun 2019. Penelitian ini dilakukan dengan menggunakan metode survei dengan teknik analisis regresi ganda. Desain penelitiannya digambarkan sebagai berikut :

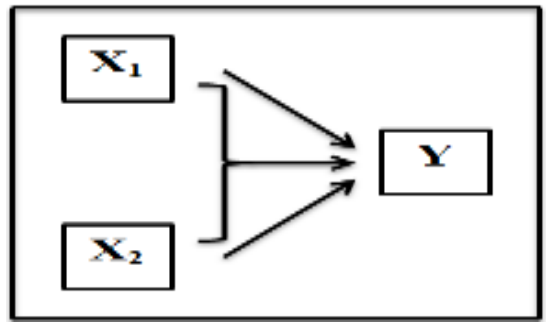

\section{Gambar 1 . Desain Penelitian}

Keterangan :

$\mathrm{X} 1$ : Kecerdasan emosional

$\mathrm{X} 2$ : Sikap siswa

$\mathrm{Y}$ : Kemampuan pemahaman konsep kimia siswa

Teknik pengambilan sampel yang dilakukan oleh peneliti dengan menggunakan random sampling. Dimana setiap bagian populasi mendapatkan kesempatan yang sama untuk dijadikan sampel dalam penelitian. Sampel yang digunakan dalam penelitian ini yaitu 90 orang siswa dari populasi 858 siswa. Sedangkan teknik pengambilan data dengan penyebaran angket untuk data kecerdasan emosional dan sikap siswa serta tes butir pilihan ganda untuk pemahaman konsep kimia.
Uji persyaratan datanya adalah Uji Normalitas, Uji Linieritas dan Uji Multikolinieritas, sedangkan untuk perhitungan statistik deskriptif dalam penelitian ini akan diselesaikan menggunakan bantuan program komputer SPSS 20.0.

\section{HASIL DAN PEMBAHASAN}

Pada skor pemahaman konsep kimia, kecerdasan emosional dan sikap siswa diperoleh data sebagai berikut :

Tabel 1. Deskripsi Data

\begin{tabular}{lrrr}
\hline & $\begin{array}{r}\text { Pemahaman } \\
\text { Konsep Kimia }\end{array}$ & $\begin{array}{r}\text { Kecerdasan } \\
\text { Emosional }\end{array}$ & $\begin{array}{l}\text { Sikap } \\
\text { Siswa }\end{array}$ \\
\hline$N \quad$ Valid & 90 & 90 & 90 \\
Missing & 0 & 0 & 0 \\
Mean & 67,12 & 89,52 & 89,14 \\
Median & 68,00 & 88,00 & 90,50 \\
Mode & 73 & $87^{\mathrm{a}}$ & 91 \\
Std. Deviation & 10,637 & 9,023 & 9,255 \\
Skewness &,- 113 &, 251 &,- 195 \\
Std. Error of &, 254 &, 254 &, 254 \\
Skewness & & & \\
Kurtosis &,- 536 &,- 441 &,- 178 \\
Std. Error of &, 503 &, 503 &, 503 \\
Kurtosis & 48 & 40 & 43 \\
Range & 41 & 70 & 66 \\
Minimum & 89 & 110 & 109 \\
Maximum & & & \\
\hline
\end{tabular}

Dari Tabel 1 terlihat untuk skor pemahaman konsep, nilai terendah 41 , tertinggi 89 , rerata sebesar 67,12 median sebesar 68, modus sebesar 73 dan simpangan baku 10,637. Skor kecerdasan emosional diperoleh skor terendah 70, skor tertinggi 110, skor rerata sebesar 89,52, median 88,00, modus sebesar 87, dan simpangan baku sebesar 9,023. Skor sikap siswa diperoleh terendah 66, skor tertinggi 109, skor rerata sebesar 89,14, median sebesar 90,50, modus sebesar 91 dan simpangan baku sebesar 9,255. Dengan demikian dapat disimpulkan bahwa pemahaman konsep kimia, kecerdasan emosional dan sikap siswa kelas X di SMA Negeri pada Jakarta Selatan tergolong cukup baik. 
Untuk mengetahui apakah data yang diperoleh penelitian berasal dari populasi berdistribusi normal atau tidak maka dilakukan Uji Normalitas dengan hipotesis: $\mathrm{H}_{0}$ : Data berasal dari populasi yang berdistribusi normal

$\mathrm{H}_{1}$ : Data berasal dari populasi yang tidak berdistribusi normal

Kriteria pengujian hipotesis :

Terima $\mathrm{H}_{1}$ dan tolak $\mathrm{H}_{0}$ jika nilai probabilitas $\mathrm{p}<0,05$.

Terima $\mathrm{H}_{0}$ dan tolak $\mathrm{H}_{1}$ jika nilai probabilitas $\mathrm{p}>0,05$.

Tabel 2. Uji Normalitas Data

\begin{tabular}{|c|c|c|c|c|}
\hline & & $\begin{array}{c}\text { Kecerdasa } \\
n \\
\text { Emosiona } \\
1 \\
\end{array}$ & $\begin{array}{c}\text { Sika } \\
\mathrm{p} \\
\text { Sisw } \\
\mathrm{a} \\
\end{array}$ & $\begin{array}{c}\text { Pemaham } \\
\text { an } \\
\text { Konsep } \\
\text { Kimia }\end{array}$ \\
\hline$N$ & & 90 & 90 & 90 \\
\hline Normal & Mean & 89,52 & $\begin{array}{r}89,1 \\
4\end{array}$ & 67,12 \\
\hline $\begin{array}{l}\text { Paramete } \\
r s^{a, b}\end{array}$ & $\begin{array}{l}\text { Std. } \\
\text { Deviatio } \\
n\end{array}$ & 9,023 & $\begin{array}{r}9,25 \\
5\end{array}$ & 10,637 \\
\hline Most & Absolute & 079 & ,079 & ,088 \\
\hline Extreme & Positive & ,079 &, 062 & ,074 \\
\hline $\begin{array}{l}\text { Difference } \\
S\end{array}$ & $\begin{array}{l}\text { Negativ } \\
e\end{array}$ &,- 060 &,- 079 &,- 088 \\
\hline \multicolumn{2}{|l|}{$\begin{array}{l}\text { Kolmogoror } \\
\text { Smirnov Z }\end{array}$} & ,748 & ,754 & ,839 \\
\hline \multicolumn{2}{|c|}{$\begin{array}{l}\text { Asymp. Sig. (2- } \\
\text { tailed) }\end{array}$} & ,630 & 621, & 482, \\
\hline
\end{tabular}

Berdasarkan hasil pengujian normalitas dengan Kolmogorov-Smirnov pada Tabel 2 didapat untuk variabel kecerdasan emosional pada mata pelajaran kimia diperoleh angka Signifikansi 0,630; selanjutnya untuk variabel sikap siswa diperoleh angka Signifikansi 0,621; dan untuk variabel pemahaman konsep kimia diperoleh angka Signifikansi 0,482. Hal ini menunjukkan bahwa distribusi data untuk masing-masing variabel adalah normal dengan demikian data masing-masing variabel penelitan memenuhi persyaratan normalitas.
Setelah uji normalitas, dilanjutkan dengan uji multikolinieritas yang tujuannya untuk menguji apakah pada regresi ditemukan adanya korelasi/hubungan yang sempurna antar variabel bebas (independent). Berdasarkan hasil pengujian didapatkan hasil Tolerance 0,622 >0,1 atau varian inflation factor (VIF) 1,608 < 10. Sehingga dapat dinyatakan bahwa tidak ada multikolinearitas antara kecerdasan emosional dan sikap siswa pada analisis regresi ganda ini.

Setelah Uji multikolinieritas dilanjutkan dengan Uji Heteroskedastisitas yang bertujuan apabila ada kesalahan atau residual yang diamati tidak memiliki varian yang konstan. Kondisi heteroskedastisitas sering terjadi pada data cross section, atau data yang diambil dari beberapa responden pada suatu waktu tertentu.

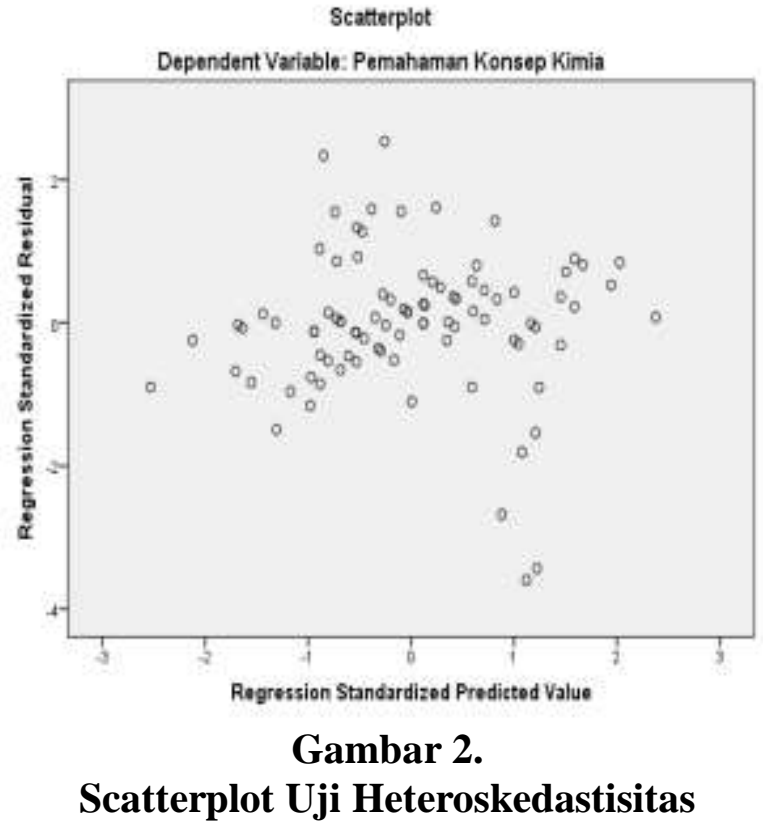

Dari gambar 2 di atas menunjukkan bahwa titik-titik membentuk pola tertentu yang jelas dan tersebar acak. Ini menunjukkan bahwa tidak terjadi heteroskedastisitas pada regresi tersebut, sehingga dapat dipakai untuk memprediksi variabel pemahaman konsep kimia berdasarkan 
kecerdasan emosional dan sikap siswa. Persyaratan regresi yang baik jika data penelitian mengikuti distribusi normal. Untuk itu dilanjutkan dengan Uji Normalitas Galat.

\section{Tabel 3. Uji Normalitas Galat}

\begin{tabular}{llr}
\hline \multicolumn{3}{c}{ One-Sample Kolmogorov-Smirnov Test } \\
& & $\begin{array}{c}\text { Unstandardized } \\
\text { Residual }\end{array}$ \\
\hline$N$ & Mean & 90 \\
Normal & Std. Deviation & $0 \mathrm{E}-7$ \\
Parameters $^{a, b}$ & Absolute &, 35415160 \\
Most Extreme & Positive &, 079 \\
Differences & Negative &,- 113 \\
Kolmogorov-Smirnov Z & 1,075 \\
Asymp. Sig. (2-tailed) &, 198 \\
\hline
\end{tabular}

Berdasarkan hasil pengujian normalitas dengan Kolmogorov-Smirnov pada tabel 3 menunjukkan bahwaa uji hipotesis yang menyatakan distribusi residual pada analisis regresi ini mengikuti distribusi normal. Hal ini ditunjukkan dengan nilai Z $=1,075$ dan Sig. $=0,198>0,05$. Hal ini berarti asumsi atau persyaratan analisis regresi terpenuhi.Jika persyaratan analisis regresi terpenuhi maka dapat dilanjutkan ke pengujian linearitas. Uji lineritas dilakukan untuk menentukan teknik dalam analisis regresi apakah variabel bebas $\left(\mathrm{X}_{1}\right.$ dan $\mathrm{X}_{2}$ ) dan variabel terikat $(\mathrm{Y})$ terbentuk linear. Uji linearitas ini menggunakan perhitungan SPSS 20.0.

Hipotesis :

$\mathrm{H}_{0}: \hat{\mathrm{Y}}=\mathrm{a}+\mathrm{bX}$ (regresi bersifat linier)

$\mathrm{H}_{1}: \hat{\mathrm{Y}} \neq \mathrm{a}+\mathrm{bX}$ (regresi bersifat tidak linier)

Kriteria pengujian hipotesis :

Terima $\mathrm{H}_{1}$ dan tolak $\mathrm{H}_{0}$ jika nilai sig. $\mathrm{p}<$ 0,05 , maka regresi bersifat tidak linier.

Terima $\mathrm{H}_{0}$ dan tolak $\mathrm{H}_{1}$ jika nilai sig. $\mathrm{p}>$ 0,05, maka regresi bersifat linier.

Tabel 4. Hasil Pengujian Linearitas Regresi Variabel $Y$ atas $X_{1}$

\begin{tabular}{|c|c|c|c|c|c|c|c|}
\hline & & & $\begin{array}{l}\text { Sum of } \\
\text { Squares }\end{array}$ & $d f$ & $\begin{array}{l}\text { Mean } \\
\text { Square }\end{array}$ & $F$ & Sig. \\
\hline \multirow{4}{*}{$\begin{array}{l}\text { Pemahaman } \\
\text { Konsep Kimia * } \\
\text { Kecerdasan } \\
\text { Emosional }\end{array}$} & & (Combined) & 7244,506 & 33 & 219,530 & 4,352 & ,000 \\
\hline & Between & Linearity & 4694,047 & 1 & 4694,047 & 93,045 &, 000 \\
\hline & Groups & $\begin{array}{l}\text { Deviation from } \\
\text { Linearity }\end{array}$ & 2550,458 & 32 & 79,702 & 1,580 & ,066 \\
\hline & \multicolumn{2}{|c|}{ Within Groups } & $\begin{array}{r}2825,150 \\
10069,656\end{array}$ & $\begin{array}{l}56 \\
89\end{array}$ & 50,449 & & \\
\hline
\end{tabular}

Tabel 5. Hasil Pengujian Linearitas Regresi Variabel $Y$ atas $X_{2}$

\begin{tabular}{|c|c|c|c|c|c|c|c|}
\hline & & & $\begin{array}{l}\text { Sum of } \\
\text { Squares }\end{array}$ & $d f$ & $\begin{array}{l}\text { Mean } \\
\text { Square }\end{array}$ & $F$ & Sig. \\
\hline \multirow{7}{*}{$\begin{array}{l}\text { Pemahaman } \\
\text { Konsep Kimia } \\
\text { * Sikap Siswa }\end{array}$} & & (Combined) & 5943,565 & 31 & 191,728 & 2,695 & ,001 \\
\hline & & Linearity & 3700,726 & 1 & 3700,726 & 52,021 & , 000 \\
\hline & $\begin{array}{l}\text { Between } \\
\text { Groups }\end{array}$ & Deviation & & & & & \\
\hline & & from & 2242,839 & 30 & 74,761 & 1,051 & , 425 \\
\hline & & Linearity & & & & & \\
\hline & Within $G$ & & 4126,090 & 58 & 71,139 & & \\
\hline & Total & & 10069,656 & 89 & & & \\
\hline
\end{tabular}

Berdasarkan dari Tabel 4 diperoleh hasil Deviation from Linearity antara kecerdasan emosional dengan pemahaman konsep kimia dengan $\mathrm{Fo}=1,580$ dan Sig. $=0,066$ 
$>0,05$. Hal ini memiliki pengertian bahwa variabel kecerdasan emosional dengan pemahaman konsep kimia mempunyai hubungan yang linear. Sedangkan pada tabel 5 diperoleh Deviation from Linearity antara sikap siswa dengan pemahaman konsep kimia dengan Fo $=1,051$ dan Sig. $=0,425>0,05$. Hal ini memiliki pengertian bahwa variabel sikap siswa dengan pemahaman konsep kimia mempunyai hubungan yang linear juga.

Setelah diyakini bahwa data yang diperoleh dari penyebaran instrumen penelitian memenuhi persyaratan analisis, selanjutnya dilakukan analisis regresi linier berganda menggunakan program SPSS 20.0. Analisis regresi linier berganda dilakukan untuk mengetahui adanya pengaruh antara variabel dependen dengan variabel - variabel independennya. Adapun persamaan regresi yang dikembangkan dalam penelitian ini sebagai berikut :

Rumus regresi linier berganda :

$$
\hat{\mathrm{Y}}=\beta_{0}+\beta_{1} \cdot X_{1}+\beta_{2} \cdot X_{2}+\varepsilon
$$

Dimana :

$\hat{Y} \quad=$ pemahaman konsep kimia

$\beta_{1}, \beta_{2}=$ koefisien variabel $\mathrm{X}$

$\beta \quad=$ konstanta

$\varepsilon=$ Error item

Penerapan model analisa regresi linier berganda adalah untuk mengukur intensitas pengaruh variabel independen terhadap variabel dependen. Untuk mengetahui variabel independen terhadap variabel dependen secara individu dilakukan melalui uji $-t$. Sedangkan untuk menguji pengaruh variabel independen terhadap variabel dependen secara bersama - sama diuji dengan uji $F$.

Kriteria pengujian hipotesis :

Tolak $H_{0}$ :Jika $F_{\text {hitung }}>F_{\text {tabel }}$

Terima $H_{1}$ :Jika $F_{\text {hitung }}<F_{\text {tabel }}$

Secara parsial :

Tolak $H_{0}$ :Jika $t_{\text {hitung }}>t_{\text {tabel }}$

Terima $H_{1}$ : Jika $t_{\text {hitung }}<t_{\text {tabel }}$

Tabel 6. Hasil Perhitungan Pengujian Koefisien Korelasi Ganda Variabel $X_{1}$ dan $X_{2}$ terhadap $Y$

Model Summary

\begin{tabular}{ccccc}
\hline Model & $R$ & $R$ Square & $\begin{array}{c}\text { Adjusted } R \\
\text { Square }\end{array}$ & $\begin{array}{c}\text { Std. Error of the } \\
\text { Estimate }\end{array}$ \\
\hline 1 &, $722^{\mathrm{a}}$ &, 522 &, 511 & 7,438 \\
\hline
\end{tabular}

Tabel 7. Hasil Perhitungan Pengujian Signifikansi Koefisien Regresi Variabel $X_{1}$ dan $X_{2}$ terhadap $Y$

ANOVA $^{a}$

\begin{tabular}{rlrrrrr}
\hline Model & & \multicolumn{1}{c}{$\begin{array}{c}\text { Sum of } \\
\text { Squares }\end{array}$} & $d f$ & \multicolumn{1}{c}{$\begin{array}{c}\text { Mean } \\
\text { Square }\end{array}$} & \multicolumn{1}{c}{$F$} & Sig. \\
\hline \multirow{4}{*}{1} & Regression & 5256,220 & 2 & 2628,110 & 47,502 &, $000^{\mathrm{b}}$ \\
& Residual & 4813,436 & 87 & 55,327 & & \\
& Total & 10069,656 & 89 & & & \\
& & & & & &
\end{tabular}


Tabel 8. Hasil Perhitungan Persamaan Regresi Ganda Variabel $X_{1}$ dan $X_{2}$ terhadap $Y$

Coefficients $^{a}$

\begin{tabular}{|c|c|c|c|c|c|c|}
\hline \multirow{2}{*}{\multicolumn{2}{|c|}{ Model }} & \multicolumn{2}{|c|}{ Unstandardized Coefficients } & \multirow{2}{*}{$\begin{array}{c}\text { Standardized } \\
\text { Coefficients } \\
\text { Beta }\end{array}$} & \multirow[t]{2}{*}{$t$} & \multirow[t]{2}{*}{ Sig. } \\
\hline & & $B$ & Std. Error & & & \\
\hline \multirow{3}{*}{1} & $($ Constant $)$ & $-16,181$ & 8,618 & & $-1,878$ & ,064 \\
\hline & $\begin{array}{l}\text { Kecerdasan } \\
\text { Emosional }\end{array}$ & ,588 & ,111 & ,498 & 5,302 & ,000 \\
\hline & Sikap Siswa & ,344 & , 108 & ,300 & 3,188 & ,002 \\
\hline
\end{tabular}

Pada Tabel 6 dapat dinyatakan bahwa terdapat pengaruh yang signifikan kecerdasan emosional dan sikap siswa secara bersama-sama terhadap pemahaman konsep kimia. Hal ini dibuktikan dengan perolehan nilai Sig. $=0,000<0,05$ dan $F_{h}$ $=47,502$. Sementara itu, persamaan garis regresi ganda dapat dinyatakan dengan $\hat{Y}=$ $-16,181+0,588 \mathrm{X} 1+0,344 \mathrm{X} 2$. Hal ini memiliki pengertian bahwa kenaikan satu skor variabel kecerdasan emosional dan sikap siswa memberikan kontribusi sebesar $58,8 \%$ oleh X1 dan $34,4 \%$ oleh X2 terhadap variabel pemahaman konsep kimia. Sedangkan secara bersama-sama variabel kecerdasan emosional dan sikap siswa memberikan kontribusi sebesar 52,2 $\%$ terhadap variabel pemahaman konsep kimia. Sisanya 47,8 \% dipengaruhi oleh faktor lain.

Pada Tabel 7 dapat dinyatakan terdapat pengaruh yang signifikan kecerdasan emosional terhadap pemahaman konsep kimia. Hal ini dibuktikan dengan perolehan nilai Sig. $=0,000<0,05$ dan $t_{\text {hitung }}=5,302$. Adapun kontribusi variabel kecerdasan emosional dalam meningkatkan pemahaman konsep kimia sebesar 24,60 $\%$. Sedangkan pada Tabel 8 dapat dinyatakan terdapat pengaruh yang signifikan sikap siswa terhadap pemahaman konsep kimia. Hal ini dibuktikan dengan perolehan nilai Sig. = $0,002<0,05$ dan $t_{\text {hitung }}=3,188$. Adapun kontribusi sikap siswa dalam meningkatkan pemahaman konsep kimia sebesar 9,69\%.
Dari hasil di atas, dapat diasumsikan bahwa untuk dapat mendukung proses belajar mengajar yang kondusif, tidak hanya diperlukan pemahaman pengelolaan dan model ajar saja dari seorang guru, akan tetapi juga terdapat faktor lain yang berasal dari dalam siswa yang dapat menjadi penentu keberhasilan seorang siswa dalam penguasaan konsep yang baik. Faktor dari dalam siswa tersebut, tidak lain diantaranya adalah kecerdasan emosional dan sikap siswa. Dalam proses belajar mengajar kecerdasan emosional memiliki peranan yang sangat penting dalam pemahaman konsep kimia, karena dengan adanya kecerdasan emosional, siswa memiliki keinginan untuk melaksanakan kegiatan belajar mengajar. Kecerdasan emosional yang tinggi dapat berpengaruh positif terhadap pemahaman konsep kimia. Sebaliknya seseorang yang memiliki kecerdasan emosional yang rendah tidak memilki tujuan yang jelas sehingga tidak mengoptimalkan usaha, sikap atau perbuatannya dalam hal ini kemampuan menalar dan menganalisis suatu permasalahan untuk meraih pemahaman konsep kimia yang baik.

\section{SIMPULAN}

Berdasarkan hasil penelitian dan pembahasan dapat disimpulkan bahwa apabila kecerdasan emosional yang ada pada diri siswa tinggi, maka pemahaman konsep siswa terhadap materi yang berhubungan dengan kimia pun akan semakin tinggi, yang pada akhirnya akan berpengaruh terhadap prestasi belajar 
siswa itu sendiri. Sebaliknya, jika seseorang memiliki kecerdasan emosional yang rendah, maka siswa tersebut tidak akan memiliki tujuan yang jelas sehingga tidak mengoptimalkan usaha atau perbuatannya untuk meraih pemahaman konsep kimia yang baik. Sama halnya apabila kecerdasan emosional yang ada pada diri siswa tinggi, maka akan memberikan sikap siswa yang tinggi pula untuk mau mempelajari mata pelajaran dalam hal ini mata pelajaran kimia dengan lebih mendalam, sehingga akan meningkat pula pemahaman konsepnya terhadap materi yang berhubungan dengan kimia, yang pada akhirnya akan berpengaruh terhadap prestasi belajar siswa itu sendiri.

\section{DAFTAR PUSTAKA}

[1] N. ROSA. "Pengaruh Sikap pada Mata Pelajaran Kimia dan Konsep Diri terhadap Prestasi Belajar Kimia". Formatif, vol. 2, no. 3, p. 234979, 2012, doi: 10.30998/formatif.v2i3.104.

[2] Firdaus Daud. "Pengaruh Kecerdasan Emosional (EQ) dan Motivasi Belajar terhadap Hasil Belajar Biologi Siswa SMA 3 Negeri Kota Palopo". J. Pendidik. dan Pembelajaran Univ. Negeri Malang, vol. 19, no. 2, pp. 243-255, 2012.

[3] E. Nauli Thaib. "Hubungan Antara Prestasi Belajar dengan Kecerdasan Emosional". J. Ilm. Didakt., vol. 13, no. 2, pp. 384-399, 2013, doi: 10.22373/jid.v13i2.485.

[4] N. Handriani dan M. Subhan, "Hubungan Kecerdasan Intelektual Kecerdasan Emosional dan Kecerdasan Spiritual terhadap Prestasi Belajar Fisika". vol. 3, pp. 1-4, 2020.

[5] A. Almubarak. "Analisis Hubungan Kecerdasan Emosional terhadap Prestasi Belajar Kimia Prodi Pendidikan Kimia FKIP ULM". Semin. Nas. Pendidik. Kim. Peran
STeM (Science, Technol. Math., pp. 233-246, 2016, [Online]. Available: http://eprints.ulm.ac.id/2580/.

[6] F. P. Nursa'adah dan N. M. Rosa. "Analisis Pemahaman Konsep Kimia Ditinjau dari Kecerdasan Intelektual (IQ), Emosional (EQ), Spiritual (SQ) dan Ketahanmalangan (AQ)". Pros. Semin. Nas. Pendidik. KALUNI, vol. 1, no. April, pp. 47-52, 2018, doi: 10.30998/prossnp.v1i0.20.

[7] H. Munandar. "Hubungan Kecerdasan Emosional dengan Hasil Belajar Siswa Kelas XI IPA SMA Negeri di Kota Parepare pada Mata Pelajaran Kimia The Correlation between Emotional Intelligence with Learning Result of Grade XI IPA Students at SMAN in Parepare on Chemical Subjec”. J. Chem., vol. 18, no. 1, pp. 39-47, 2017.

[8] A. Wiyono, M. Anggo, dan K. Kadir. "PENGARUH KECERDASAN EMOSIONAL TERHADAP HASIL BELAJAR MATEMATIKA SISWA KELAS VIII mts NEGERI 1 KENDARI". J. Penelit. Pendidik. Mat., vol. 6, no. 2, p. 113, 2019, doi: 10.36709/jppm.v6i2.9121. 